\title{
THE PROBABILITY OF RETURN CONDITIONAL ON MIGRATION DURATION: EVIDENCE FROM KOSOVO
}

Mrika Kotorri

\begin{abstract}
The aim of this paper is to conceptualise the migration duration decision within the expected utility maximisation framework, and from that to derive and estimate an empirical proposition. For this purpose, the conceptual framework in Kotorri (2015) is extended where households decide to return to the home country conditional on their migration duration. In the empirical analysis, the Cox proportional hazards model is employed. This analysis is the first to investigate migration duration based on a random sample stemming from the Kosovo census of population conducted in 2011. The findings suggest rather mixed support for the household approach. The hazard to return decreases with income but not nonlinearly. The results indicate that household return migration behaviour is influenced by demographic characteristics, psychic income, and political factors.
\end{abstract}

Keywords: Return, Migration, Duration, Survival Analysis

JEL Classification: J60,D1, 015

\section{INTRODUCTION}

Kosovo has a long migration experience, which has passed through three waves, and a large number of its population lives abroad. According to the latest census of the migrant population undertaken by the Ministry of Diaspora, around 400,000 Kosovans live abroad. The motivation of this analysis is that due to the large share of the Kosovan population living abroad, the characteristics of migrant households that return are important from the perspective of Kosovo's future economic development. This renders the analysis of whether the probability of return is higher among the more or the less educated valuable to find out whether Kosovo is benefiting from Brain Gain. If the poor and elderly are more likely to return, this will increase the future burden on the currently weak welfare system in Kosovo. Usually, returnees transfer savings and know-how through business investments fostering economic growth at home. So, the demographic and economic characteristics of returnees are also worth investigating.

In the return migration literature, Dustmann (2002) and Dustmann and Weiss (2007) recognise that both temporary and circular migration occurred, irrepsective of persisting wage differentials. Azzari and Carletto (2009) argue that analysing the migration process by ignoring its dynamic and repetitive nature

Mrika Kotorri, PhD

Assistant Professor of Economics

Head of the Department of Economics

University of Prishtina, Faculty of Economy

Assistant Professor of Economics at Rochester

Institute of Technology Kosovo

E-mail: mrika.kotorri@gmail.com 
may be limited and misleading. Accordingly, studies adjust the theoretical framework and model migration as a dynamic process within an optimal lifecycle framework.

Given the above, the aim of this paper is to extend the theoretical framework deployed in Kotorri (2015) to investigate the determinants of the optimal migration duration among Kosovan migrant households. Hence, migration is modelled as a dynamic household decision. This phenomenon has been recognised by a rather low number of migration studies.

This paper contributes to knowledge in several respects. It slightly extends the conceptual framework developed in Kotorri (2015) adding the effects of business ownership and house ownership. These two are hypothesised to capture aspects of psychic income different from those controlled for by existing variables. Second, it is the first to test the applicability of the household perspective and employ the Cox proportional hazards model in investigating migration duration among Kosovan households based on a sample derived from the latest Kosovo census. Third, given this, it contributes to knowledge by providing policy implications of return migration based on more accurate results compared to those in Kotorri (2015), as the survey of that analysis was based on the 2004 Voters Official Registry.

\section{LITERATURE REVIEW}

This literature review focuses exclusively on theoretical models developed in the migration literature ignoring empirical results, for brevity. Following differences in the theoretical approaches are considered.

Early studies, modelled emigration and return as one decision within the optimal lifecycle approach focussing exclusively on its determinants (Borjas and Bratsberg 1996; Kotorri 2010; Efendic 2016). One of the limitations of this framework is that it ignores the relevance of time. Time is rendered important in influencing the return decision, if the emigration reason is related to a savings target. Due to differences in employment and earnings abilities, some migrants may never manage to reach their savings target and hence not return. So, differences in migration and remigration costs over time among migrants, and differences in returns conditional on migration duration are relevant too. But it is impossible to integrate migration duration within this model as it assumes constant migration and remigration costs and constant returns to migration spells among migrants. Several studies analyse the return decision ignoring the importance of duration (Waldorf 1995; de Coulon and Piracha 2005; de Coulon and Wolff 2006; Sander 2007; Kotorri et al. 2013).

To fill this gap, some studies amend the conceptual approach to consider the relevance of time. These studies conceptualise the return decision in terms of migration duration, rather than the probability of return (Djajic and Milbourne 1988; Dustmann 2002; Carrion-Flores 2006; Dustmann and Weiss 2007; Gundel and Peters 2008; Azzari and Carletto 2009; Gaule 2011). The first three studies provide a conceptual analysis in addition to the empirical investigation of the determinants of migration duration. For illustration the theoretical approach in Dustmann (2002) is discussed below. Carrion-Flores (2006) elaborates a conceptual framework identical to that in Dustmann (2002), but does not make reference to it.

Employing the individual perspective, Dustmann (2002) models the return decision by weighting the benefits of staying an additional time unit against the costs of it. This is then maximised given a budget constraint. Here, the migration duration is maximised conditional on wage differentials, consumption preferences, relative price of consuming in the host country and cost of migration. The relationship between the wage deferential and migration duration is assumed to be ambiguous. Due to the relative wage effect, an increase in the wage differential positively impacts on the marginal benefit of staying abroad leading to longer migration duration. Yet, the income effect works in opposite direction. As wage differentials increase the lifetime wealth, given diminishing marginal utility from wealth, migrants have a lower incentive to stay abroad for another period. Because of this ambiguity, wage cannot be considered the only determinant of migration duration rendering other factors important. The author hypothesises that the preference for consumption at home and the purchasing power of the host country currency at home are relatively higher. Thus, irrespective of better economic conditions abroad, migrants may return due to the greater utility from consumption at home. Migrants benefit from longer migration duration because of the assumed positive wage differential in favour of the host country, and/or preferences and favourable relative prices. Hence, migration duration is considered to have a positive impact on migrants' lifetime wealth. Migration costs include the forgone utility from consumption at home. Given the hypothesis on the relatively higher preference for consumption at home or the hypothesis on the relatively higher purchasing power of the host country currency at home, or both, migration costs are positive and increase with migration duration. Consequently, the migration duration is optimal when the expected total benefits equal the 
total costs of staying one extra time unit. Unlike Borjas and Bratsberg (1996) they introduce heterogeneous migration costs among migrants. Arguing that return migration may be a result of the return to the human capital acquired/accumulated in the host country being higher at home, Dustmann and Weiss (2007) enrich this model to integrate the relevance of human capital.

This model is further amended by integrating the possibility of different activity choices upon return into the optimal migration duration (Dustmann and Kirchkamp 2002). Piracha and Vadean (2010), and Borodak and Piracha (2011) deploy a similar framework allowing for the option of jointly deciding on return and activity choice, but ignore migration duration. Later, the theoretical approach was adjusted to consider the possibility of circular migration (Azzari and Carletto 2009; Vadean and Piracha 2010). Circular migration is not common among Kosovan migrants. A discussion on these extensions is not provided here given that it is out of the scope of this research.

The studies reviewed above, deploy either the individual or the eclectic approach to model the return decision. To fill this gap, Kotorri (2015) conceptualises return migration using the expected utility maximisation framework from the perspective of the household. In this paper, to analyse factors influencing the probability to return conditional on the length of stay abroad, the framework developed in Kotorri (2015) is extended. This extension is explained in detail in the section on Model Specification.

\section{SURVEY AND DATA}

This analysis is performed using a sample stemming from a survey of 1,600 Kosovan households conducted in 2012. The survey was based on the latest census of population (Kotorri et al. 2013). The sample is stratified by region, and within regions it is stratified by type of area, urban and rural. This was done to ensure representativeness, which is a key prerequisite for the accuracy of results. The observation unit is the household and household heads were directly interviewed. The survey was conducted by Economic Development Group in 2012 for the purposes of analysing migration and its accompanying components on the economic development of the home country. Accordingly, the data set contains information on both household members at home and those abroad. For this analysis, variables are created using the section on household members abroad which contains information on both those who are abroad and those who have returned. Hence, the total sample used for this analysis is reduced to 418 observations. Henceforth, migrant household refers only to that part of the household that is living or has lived abroad.

Given the focus of the investigation, the questions of interest are "in what year has the migrant household emigrated?", "has the migrant household returned permanently to Kosovo?", and "in what year has the migrant household returned to Kosovo?". As presented in Table 1, descriptives show that out of the total of 418 migrant households 64 have returned permanently to Kosovo.

Table 1: Migrant households, return migrant households and migration duration

\begin{tabular}{|l|r|}
\hline Migrant households & 418 \\
\hline Permanently return migrants & 64 \\
\hline Shortest migration duration, years & 0.5 \\
\hline Longest migration duration, years & 56 \\
\hline Average migration duration, years & 14 \\
\hline Standard deviation of migration duration, years & 8.63 \\
\hline
\end{tabular}

There is a very high difference between the longest (56 years) and the shortest time spent abroad $(0.5$ years) by migrant households, 55.5 years. The mean of the migration duration is 14 years, which is relatively low, around one-fourth of the longest time span. The standard deviation is 8.63 years.

Similar to empirical analyses using survey data, this analysis too suffers from missing data. Data missingness is the results of giving the respondents the option of refusing to answer. In this context, deploying listwise deletion (LD) implies ignoring incomplete cases resulting in loss of information, and as a consequence in inflated standard errors and reduced level of statistical significance. Also, potential systematic differences between the incomplete and complete cases are ignored which leads to inaccurate results. Thus, it is highly recommended that one uses techniques that handle missing data, such as multiple imputation (MI). Yet, LD is appropriate if data follow the missing completely at random mechanism (MCR). This implies that sample representativeness is not affected by data missingness and, in turn, the accuracy of results is not harmed. However, Little and Rubin (2002) consider that in survey data the MCR is too strong an assumption, and Cameron and Trivedi (2005) argue that it is nontestable. Given these arguments, multiple imputation to address data missingness is not performed in the empirical investigation reducing the sample size to 290 complete observations. Hence, it may be considered a limitation. Another limitation of 
this investigation is the shortcomings associated with self-declaration. All variables, including the dependent variable (whether the household has returned and its migration duration) are self-reported rather than stemming from any official documents which could serve as proof for the declarations. Although they are not recognised explicitly, such limitations are a common characteristic of the empirical analyses reviewed above. Yet, for the purposes of our empirical investigation this sample data is one of the most adequate and rich sources of information available in Kosovo, despite its limitations. It is important to admit that focussing only on migrant households is a limitation of this analysis given the household approach.

\section{MODEL SPECIFICATION}

This analysis extends the conceptual framework elaborated in Kotorri (2015) and, thus, is built on the same basis as that developed in Kotorri (2010). Given social relations and the dominant system of values within Kosovan households and the absence in the literature of a fully articulated and consistent theoretical framework, Kotorri (2015) develops an initial theoretical framework for analysing household behaviour within the expected utility maximisation framework. She elaborates and examines several complementary hypotheses, aiming at investigating the applicability of the household approach in describing migration behaviour among KS-households. The results of both empirical investigations provide broad support for the validity of a household perspective in modelling migration decisions. Consequently, the household approach is deployed. Accordingly, return migration is modelled within the household decision-making process where the household as a whole tries to maximise utility subject to its income constraint. The maximisation problem varies according to two choices facing the household: 1) remain in the host country for an additional period or 2) return permanently to the home country. This theoretical framework guides the specification of hypotheses on the economic migration duration from the household perspective. Even though the theoretical framework is an extension of that developed in Kotorri (2015), for ease of following the empirical investigation it will be reproduced in full below and differences will be emphasised.

Prior to elaborating the extended conceptual framework, issues regarding endogeneity relating to return migration behaviour are discussed. Kotorri (2015) argues that Kosovan emigration consists of three waves and that return migration was rather unusual. The first wave is characterised by emigration based on labour programmes, the second by legal and illegal emigration for both political and economic reasons, and the last wave consisted of forced emigration. After 1989, the political situation worsened tremendously leading to return migration becoming extremely difficult. Back then, in case of visits to the home country, even for migrants with host country citizenship return to the host countries was uncertain. Uncertainty of return to the host country was even higher among illegal migrants most of whom did probably not even have legal residence abroad. Given Kosovo's great geographic distance from the host countries, successful re-emigration may have been very costly and less certain for both legal and illegal migrants visiting Kosovo. Consequently, it is assumed that there is no difference in unobserved characteristics between return migrant households and nonreturn migrant households which may impact on the return decision. Accordingly, the return decision is not expected to be endogenously determined. So, no bias in the empirical results is expected.

Given the nature of the empirical technique, the dependent variable is specified as the instantaneous hazard of return conditional on the current migration duration. For return migrant households, the migration duration is calculated as the difference between the year of initial emigration and permanent return. For non-return migrant households this is measured as the differences between the year of the initial emigration and the year of the survey.

\section{Pecuniary income}

For reasons explained in Kotorri (2015), the impact of pecuniary income is captured by current average gross monthly income per capita (YA). Given household budget constraints and the cost of return, lowincome households are assumed to need more time to accumulate capital in case of return. Hence, income has a positive impact on migration duration, all else equal. Yet, after a certain level of income is achieved, due to the diminishing marginal utility from wealth, the effect of this variable on the hazard to return is expected to be negative, all else equal. Accordingly, income is expected to have a non-linear relationship with the hazard to return. This effect is captured by introducing average monthly household income per capita abroad and its squared term.

Following Kotorri (2015), household demographic characteristics are introduced to reflect other wealth aspects. In case these variables capture other effects, it is discussed along with their definition.

Given the lower probability of finding paid 
employment in Kosovo, having a higher share of those in working age who are in employment (SWAE) makes households perceive the risk related to return more strongly as they would have to leave their paid employment. Thus, SWAE is hypothesised as having a negative impact on the return hazard. To capture this effect, SWAE is introduced as a continuous variable.

It is expected that females are affected more than males by perceived undesirable social customs in host countries. Following this argument, households with a larger share of females are a priori assumed to prefer consumption in the home country. So, share of females (SF) is expected to have a positive impact on the hazard to return and is introduced as a continuous variable.

The educational attainment of the household head is use to proxy for human capital within the household. The better educated households are assumed to be more likely to have information on employment opportunities in host countries and better knowledge of foreign languages. Hence, they are hypothesised as having a higher probability of socio-economic integration leading to a lower hazard to return. However, they may have a lower likelihood of finding adequate employment abroad due to possible low interregional mobility of their skills and diplomas (Eggert, Krieger and Meier, 2010). Also, Borjas and Bratsberg (1996) argue that host countries are a type of magnet for the less educated. This leads to the better educated having a lower likelihood of being successful in the labour market, which in turn, reduces the likelihood of them experiencing appropriate socio-economic integration in the host country. Further, due to labour market premia in the Kosovan labour market, the better educated may be more willing to return. Hence, such households may perceive the utility from consumption at home to be greater increasing the hazard to return, all else equal. Following these arguments, a priori this variable is expected to have an ambiguous effect.

\section{Psychic income}

In addition to the household demographic characteristics introduced above, this analysis controls for the impact of whether the migrant household consists of only one member (Individual). However, unlike Kotorri (2015), this investigation is extended by introducing household size to capture other aspects of the effect of social interactions. The variable Individual is assumed to capture an effect similar to that of networks introduced in Kotorri (2010). So, it is hypothesised to have a negative effect on migrants' destination-specific utility leading to an a priori positive impact on the hazard to return, all else equal. This effect is captured by a dummy variable taking the value of one if the migrant household consists of only one member, zero otherwise. Unlike this variable, household size is assumed to control for the effect of family ties within the migrant household. So, a larger household size enables greater benefits from social interactions leading to higher psychic income in the host country, all else equal. It may also control for the nonlinear effect of continuous migration costs derived from economies of scale. Household size is expected to have a positive impact on psychic income lowering the hazard to return, all else equal.

Studies reviewed above suggest that having the citizenship of the host country is considered a specific social investment by migrant household. As such, it is modelled to control for the impact of greater preference for consumption in the host country resulting from increased socio-economic integration. Such households are expected to have a lower hazard to return, all else equal. To capture this effect a dummy variable is constructed taking the value of one if the household has the citizenship of the host country and zero otherwise.

Whether any household member has attained education at institutions in the host country is a variable that is hypothesised to capture another aspect of specific investments of migrant households. As such, this variable is expected to control for the impact of the greater destination-specific utility in the host country resulting from the increased level of socio-economic integration of members attaining or having attained education abroad. It is hypothesised to have a negative impact on the hazard to return. This variable is introduced as a dummy variable taking the value one if any member of the migrant household has or is attaining education abroad.

Unlike Kotorri (2015) and following the strategy of studies reviewed above, two additional variables are included, house ownership and business ownership among migrant households. In addition to an income effect, both capture different aspects of the effect of household psychic income. Hence, their effects are in principle different from that of income.

Owning a house in the host country is considered to capture yet another aspect of specific investment leading to an increased preference for consumption in the host country. This variable is expected to control for the effect of increased preference for consumption abroad due to the greater level of socio-economic integration. Moreover, if the household has used a mortgage to buy a house it will be legally bound to pay it back. Consequently, such households are likely 
to have a longer migration span. Accordingly, a priori owning a house abroad is expected to negatively impact on the hazard to return, all else equal. To capture this effect a dummy variable is introduced taking the value one if the household owns a house, zero otherwise.

Whether the household owns a business abroad is expected to capture the effect of the preference for consumption in the host country resulting from the increased economic integration abroad. Owning a business implies intensive engagement and continuous management and oversight. So, this effect is different from that of owning a house. This variable is hypothesised as having a negative impact on the hazard to return. Yet, given that such households are expected to be more entrepreneurial and given social ties with household members at home, such households may have greater incentives to return for investment purposes. Hence, the a priori sign of this variable is inconclusive. It is constructed as a dummy variable taking the value one if the household owns a business abroad, zero otherwise.

\section{Political situation}

As argued above and following Efendic (2016) migration behaviour is affected by political stability. Accordingly, the decisions on return migration and migration duration of households that emigrated during the 1998/1999 war in Kosovo may be influenced by political rather than economic factors. Such migrant households are expected to be more likely to return to Kosovo and more likely to have a shorter migration duration. This specific political effect is controlled for by a dummy variable taking the value of one if emigration took place in 1998 or 1999 , zero otherwise. The variable is expected to positively impact on the hazard to return.

As introduced above, the dependent variable is the instantaneous hazard of return conditional on the current duration of migration. The issue here is that the dependent variable is characterised by right-censoring. Households, which continue their migration spell after the year of the survey, are considered as right censored observations, whereas households, which have returned to the home country, are considered as having 'failed'. Right-censoring, which is a problem in linear regressions, can be handled by deploying censored normal-regressions. Possible techniques within this framework are also binary analysis methods. These have the advantage that they do not impose any assumption on the distribution of failure time. However, they focus only on the probability of return ignoring differences in migration durations and thus lead to the inefficient use of the data (Cleves, Gould and Gutierrez 2002).

Given these arguments, other techniques are required. In this context, the Cox proportional hazards model is an appropriate technique as it does not assume normality and so overcomes issues which render binary regression models problematic. It also efficiently uses the data by considering both return and migration duration.

The Cox model is a semi-parametric model, which takes the form of Equation (1.1). The dependent variable is the instantaneous hazard of return to the home country of the household at time $t$, conditional on migration duration and is a function of the independent variables (covariates) and an unknown and arbitrary baseline hazard function of time:

$$
h_{i}(t)=h_{0}(t) \exp \left(x_{i}^{\prime} \beta_{x}\right)
$$

where $h_{j}(t)$ is the hazard of return migration of household $i$ at time $t$ conditional on having survived up to time $t$, that is, conditional on having remained in the host country up to time $t$, and $h_{0}(t)$ is the baseline hazard rate. $x_{j}$ is a vector of explanatory variables, consisting of pecuniary income (py), a set of variables representing psychic income (psy), and a set of variables representing migration costs $(\mathrm{mc})$, while $\beta_{\mathrm{x}}$ is a column vector of regression coefficients.

This model is based on the proportionality assumption which implies that the effect of the covariates is proportional over the entire baseline hazard (Cleves, Gould and Gutierrez 2002). So, irrespective of its shape the baseline hazard function is the same for all observations and the hazard rate of an observation depends only on the covariates. This assumption represents the key issue when deploying the Cox model (Box-Steffensmeier and Jones 2004) and it can be tested by standard tests, which are based on residuals.

Key to this method is the estimation of regression parameters, while the baseline hazard in which the intercept is subsumed is not estimated (Cox 1972; Cleves, Gould and Gutierrez 2002). This advantage is particularly important in a context where no adequate assumptions about the shape of the hazard can be made (Cleves, Gould and Gutierrez 2002). Any incorrect assumptions would lead to efficiency loss and consequently inaccurate results.

Guided by the theoretical framework and based on the above, the empirical model is presented in Equation 1.2 (all the terms are defined above):

$h_{i}(t \mid p y, p s y, m m)=h_{0}(t) \exp \left(\beta_{1} p y+\beta_{1} p s y+\beta_{1} m c\right)$ 


\section{EMPIRICAL ANALYSIS}

The Cox model is estimated using the maximum partial likelihood method. This method has large sample properties. As this empirical investigation is based on a sample of around 418 observations (migrants' households) of which 64 are failures (return migrants' households), the importance of sample size and baseline risk in Cox models regarding biasness is discussed. Adam et al. (2004) investigate the bias of ML estimators in small samples by comparing Maximum Likelihood (ML) and the Method of Moments (MOM). The authors run a number of simulations by allowing sample size to increase and argue that the ML estimator of the variable of interest is considerably upward biased for samples smaller than 50 observations. Further, they find that the sample size must be at least 220 (450) observations so that the bias of the ML estimator be smaller than 10 (5) per cent. Given that this analysis is based on a sample size of slightly less than 450 observations, one may expect a bias of around 5 per cent.

Biasness is also dependent on the number of failures in the sample. Samples with a number of failures less than 5, and sometimes less than 10, are considered to be small. Hence, the MLEs can be biased estimators of the true population and the large sample properties may not apply leading to bias in Cox models. Yet, this does not apply to this analysis, as the number of failures in this sample is 64 .

Following the results from the Cox model of the probability of return conditional on migration duration are interpreted. Given the discussion above, the results have to be considered with caution regarding biasness resulting from small sample size and low number of failures in the sample.

\section{Diagnostics tests}

Prior to the interpretation of empirical results, as suggested in Cleves, Gould and Gutierrez (2002) the proportional-hazards assumption and the predictive power of the model are tested. The Schoenfeld test of the proportional-hazards assumption is based on the examination of residuals. Results indicate that the proportional hazards assumption is not violated, chi2 $(12)=20.27$ and $p=0.06$. The Harrell's $C$ concordance statistic is used to evaluate the predictive power of the Cox model. This statistic can take values between zero and one. A value of 0.5 implies no predictive power. In this analysis, the Harrell's $C$ statistic is 0.85 which is greater than the reference statistic of 0.5 suggesting that the predictive power of the model is relatively good.
The exponential of the estimated coefficients are taken to give the hazard ratios for a one-unit change in the corresponding covariate. The direction of the impact of exponentiated coefficients is determined based on whether the coefficient is lower or greater than one. A negative impact is implied by the former case, while a positive by the latter (Cleves, Gould and Gutierrez 2002).

As shown in Table 2, contrary to expectations results provide no support for the inverse U-shaped relationship between migrant household average monthly income per capita and migration duration. Results indicate that the relationship is linear and negative. So, household income has a negative impact on the hazard to return to the home country, all else equal. Of the variables capturing the effect household demographic characteristics the only statistically significant variable is the share of females. Empirically, we find that having a larger share of females in the household reduces the hazard to return. This is inconsistent with the hypothesis that in Kosovan migrant households females may be more likely to be affected than males by perceived negative social customs in the host country. An explanation could be that females are more likely to appreciate and adopt the host-country specific system of values allowing for more freedom of choice for the individual leading to a stronger socioeconomic integration and so lower hazard to return. A priori, the expected sign of the impact of the household head having higher education was ambiguous. Results suggest that it has no significant impact, implying that the estimates do not provide support for either hypothesis.

Among the variables controlling for the impact of psychic income, the dummy variables Citizenship and Houseownership are statistically significant. However, the latter variable is statistically significant only at $10 \%$ level. Theoretically, they are expected to have a negative impact on the hazard to return. Results suggest that households that have the citizenship of the host country have a lower hazard of return. This supports the hypothesis that households having the citizenship of the host country have a higher level of socio-economic integration, implying that they have a higher preference for consumption in the host country. Households owning a house abroad are found to have a greater hazard to return. This contradicts the hypothesis that such households have a greater preference for consumption in the host country given their investments. Although statistically insignificant $(p=0.11)$, probably due to being statistically not well defined, owning a business has a very strong positive impact on the return hazard.

Theoretically, it is argued that households that 
Table 2: The estimated determinants of migration duration

\begin{tabular}{|c|c|c|c|}
\hline Variable & Hazard Ratio & $P>|t|$ & Expected sign \\
\hline \multicolumn{4}{|l|}{ Household Characteristics } \\
\hline YA & 0.99 & $0.06^{* *}$ & Greater than 1 \\
\hline YASQ & 1 & 0.90 & Less than 1 \\
\hline SWAE & 0.99 & 0.30 & Less than 1 \\
\hline SF & 0.98 & $0.04^{* *}$ & Greater than 1 \\
\hline Education & 1.2 & 0.66 & Ambiguous \\
\hline \multicolumn{4}{|l|}{ Psychic Income } \\
\hline Individual & 0.53 & 0.29 & Less than 1 \\
\hline Householdsize & 0.81 & 0.28 & Less than 1 \\
\hline Citizenship & 0.30 & $0.01^{* * *}$ & Less than 1 \\
\hline Edulnstitution & 0.59 & 0.30 & Less than 1 \\
\hline Houseownership & 1.85 & $0.10^{*}$ & Less than 1 \\
\hline Businessownership & 2.30 & 0.11 & Ambiguous \\
\hline \multicolumn{4}{|l|}{ Political situation } \\
\hline Year1998/99 & 3.01 & $0.01^{* * *}$ & Greater than 1 \\
\hline Number of observations & 290 & & \\
\hline Number of failures & 39 & & \\
\hline Time at risk & 42.41 & & \\
\hline LR chi2(12) & 68.50 & 0.001 & \\
\hline Log likelihood & -147.23 & & \\
\hline $\begin{array}{l}\text { Test of the proportional-hazards based on the } \\
\text { Schoenfeld residuals chi2(12) }\end{array}$ & 20.27 & 0.06 & \\
\hline Harrell's C concordance statistic & 0.85 & & \\
\hline
\end{tabular}

have emigrated during the war makeup a specific group for which, at least, the initial emigration motive may be considered as forced. Thus, such households are expected to have a greater hazard to return compared to households that belong to migration waves that took place before or after the war. Empirically, we find a strong statistically significant difference (at the $1 \%$ level) in the return decision between the two groups. Households that have emigrated during the war have a three times higher hazard to return compared to the reference group, all else equal.

The household approach deployed here is more limited than that deployed in Kotorri (2010) due to the definition of the household, resulting from missing data on the part of migrant or non-migrant households. Overall the results are not completely in line with the theoretical expectations of the model. Out of the variables for which theoretically the signs were statistically clearly defined, for six of them the results are in line with the theoretical expectations: share of those of working age employed, household size, citizenship, education institution, and the year dummy. However, only one of them is statistically significant. Education and Businessownership are the only variables for which the a priori impact was not clearly defined. Empirically, both have a positive but insignificant effect. It is important to note that the statistical insignificance may be due to cancelling out of opposing effects. Inconsistency with theoretical expectations is found regarding the variable that controls for the share of females within the household, whether the migrant household consists of one member only, whether the household owns a house and whether the household owns a business. Yet, with the exception of share of females the other variables are not statistically significant.

As a sensitivity analysis, the model specification in Kotorri (2015) is estimated using this sample (Appendix 2). The results are almost identical to those reported in Table 2. 
CONCLUDING REMARKS AND POLICY

\section{RECOMMENDATIONS}

In this paper, the conceptual framework of Kotorri (2015) is extended and an empirical model is specified to investigate the determinants of the probability to return conditional on migration duration. It is estimated using the Cox model on a sample of over 400 Kosovan migrant households.

The diagnostic tests indicate that the predictive power of the model is relatively strong and overall the model is correctly specified providing support for the hypothesis that there is no evidence of non-proportional hazards, which is a fundamental consideration with the Cox model. The results provide mixed support for the theoretical expectations of the model raising doubts about the applicability of the household approach in modelling return migration. One explanation could be that, as acknowledged, given the definition of the household, this household approach is considered more limited than that deployed in Kotorri (2015). Another explanation for this may be that migrant households while going through a process of socioeconomic integration adopt social customs and norms specific to host countries. Thus, the Kosovan social relations and the system of values among migrant households fade away. These results warrant further research on the applicability of the household view given the arguments in favour of it provided in Kotorri (2010).

Contrary to Kotorri (2015), there is no evidence of the hypothesised non-linear relationship between income and the hazard to return. Similar to results of this research, Carrion-Flores (2006) finds the impact to be significantly negative and linear.

Unlike Carrion-Flores (2006) and Gundel and Peters (2008), higher levels of education are not found to have a statistically significant effect on return. From a policy perspective, this analysis does not provide support for either a Brian Drain or Brain Gain from return migration. Contrary to Kotorri (2015), there is no support for a Brain Gain resulting from the higher probability of return if the household has members educated or attaining education in the host country. Although statistically insignificant, this variable actually has a negative impact on the hazard to return.

Similar to Kotorri et al. (2013), that ignore the time relevance, but contrary to Kotorri (2015), the findings indicate that having a higher share of females implies a lower hazard to return. An explanation for this may be that Kosovan females prefer the position of the female within the foreign system of values resulting in a faster socioeconomic integration abroad.

Having the citizenship of the host country and owning a house are statistically significant. The former variable has the expected negative sign which supports the hypothesis put forward earlier on such households have a higher preference for consumption abroad. Although they used a slightly different variable, the results in Gundel and Peters (2008) and Sander (2007) show a similar effect. Contrary Gundel and Peters (2008) and Sander (2007), findings reveal that owning a house increases the hazard to return. However, this variable is only statistically significant at the $10 \%$ level. Businessownership, although statistically insignificant reveals that such households have a greater hazard to return.

Similar to Kotorri (2015) and Kotorri et al. (2013) and in line with empirical findings in Efendic (2016) about the importance of political factors in shaping migration behaviour, as well as consistent with theoretical expectations, results indicate that migrant households that have emigrated during the war have a higher hazard of return. This finding supports the relevance of the war effect on migration behaviour among Kosovan households.

In sum, the statistically significant effect of the income variable, having the host country citizenship controlling for the effect of socioeconomic integration and this strong effect of the variable controlling for the effect of political events suggest that the return migration behaviour of Kosovan migrant households is determined by both economic and non-economic factors.

Due to the large number of Kosovan migrants and their potential benefits to fostering development, it is important to derive policy recommendations. The findings reveal that those that have businesses in the host countries are more likely to return suggesting the need for policies aiming at improving the business environment and business investment promotion policies to encourage migrants to return and invest utilising their financial and human capital, and business networks. Second, such policies should focus on maintaining cooperation among the Kosovo government, Kosovo-based business associations and migrant host-country based business associations in identifying investment opportunities, and the need for customised support in establishing businesses and other relevant government support instruments.

The Kosovo government is implementing repatriation programmes with host countries. As return migration is more likely among those that have emigrated during the 1998/9 War and lower-income households, it is recommended that the government continues these programmes in the future. Stronger emphasis within these programmes should be put on supporting returnees in acquiring education and training upon return and providing speedy and low cost accreditation of qualifications for those that have 
acquired human capital abroad. Such programmes should focus on potential returnees in general.

Additionally, in the world of technological advance, policies should focus on lowering travel costs rather than communication costs to encourage the maintenance of family ties between migrant and non-migrant members and migrants' ties with the home country. In turn, such policies would encourage return. Lastly, to ensure their effectiveness, policy recommendations should be followed by evaluation strategies.

\section{REFERENCES}

Adam, E., Quivy, V., Bex, F., Chariot, A., Collette, Y., Vanhulle, C., Schoonbroodt, S., Goffin, V., Nguyên, T.L.A., Gloire, G. and Carrard, G. 2004. Potentiation of Tumor Necrosis FactorInduced NF-KB Activation by Deacetylase Inhibitors Is Associated with a Delayed Cytoplasmic Reappearance of IKBa. Molecular and cellular biology 24 (15): 6890-6890.

Altman, D. G., De Stavola, B. L., Love, S. B., and Stepniewska, K. A. 1995. Review of Survival Analyses Published in Cancer Research. British Journal of Cancer, 72 (2): 511-518.

Azzarri, C. and Carletto, G. 2009. Modelling migration dynamics in Albania: a hazard function approach. Southeast European and Black Sea Studies 9 (4): 407-433.

Borjas, G. J. and Bratsberg, B. 1996. Who Leaves? The Outmigration of the Foreign-Born. Journal of Economics and Statistics 78 (1): 165-176.

Borodak, D. and Piracha, M. 2011. Occupational choice of return migrants in Moldova. Eastern European Economics 49 (4): 24-46.

Box-Steffensmeier, J. M. and Jones, B. S. 2004. Event history modeling: A guide for social scientists. Cambridge University Press.

Cameron C. A. and Trivedi, P. K. 2005. Microeconometrics: Methods and Applications. Cambridge University Press.

Carrión-Flores, C. E. 2006. What makes you go back home? Determinants of the duration of migration of Mexican immigrants in the United States. Society of Labor Economists Annual Meeting, Cambridge MA.

Chiozza, G., and Goemans, H. E. 2004. International conflict and the tenure of leaders: Is war still ex post inefficient?. American Journal of Political Science 48 (3): 604-619.

Cleves, M., Gould, W., and Gutierrez, R. 2002. An Introduction to Survival Analysis Using Stata. College Station, TX: Stata Press.

Cox, D. R. 1972. Regression models and life-tables (with discussion). Journal of Royal Statistical Society 34: 187-220.

de Coulon A. and Piracha, M. 2005. Self-Selection and the Performance of Return Migrants: The Source Country Perspective. Journal of Population Economics, 18 (4): 779-807. de Coulon, A. and Wolff, F-C. 2006. The Location of Immigrants at Retirement: Stay/Return or "Va-et-Vient"? IZA Discussion Paper 2224.

Djajic, S. and Milboume, R. 1988. A General Equilibrium Model of Guest Worker Migration. Journal of International Economics, 25 (3-4): 335-351.

Dustmann, C., and O. Kirchkamp. 2002. The optimal migration duration and activity choice after re-migration. Journal of Development Economics 67 (2): 351-372.

Dustmann, C. 2003. Return migration, wage differentials, and the optimal migration duration. European Economic Review 47 (2): 353-369.

Dustmann, C., and Y. Weiss. 2007. Return migration: theory and empirical evidence from the UK. British Journal of Industrial Relations 45 (2): 236-256.

Efendic, A. 2016. Emigration intentions in a post-conflict environment: evidence from Bosnia and Herzegovina. Post-Communist Economies 28 (3): 335-352.

Eggert, W., Krieger, T., and Meier, V. 2010. Education, unemployment and migration. Journal of Public Economics 94 (5): 354-362.

Gaule, P. 2011. Return Migration: Evidence from Academic Scientists. Mimeo.

Grambsch, P. M. and Therneau, T. M. 1994. Proportional hazards tests and diagnostics based on weighted residuals. Biometrika 81 (3): 515-526.

Gundel, S. and Peters, H. 2008. What Determines the Duration of Stay of Immigrants in Germany? International Journal of Social Economics 36 (11): 769-782.

Keele, L. 2010. Proportionally Difficult: Testing for Nonproportional Hazards in Cox Models. Journal of Political Analysis 18 (2): 189-205.

Kotorri, M. 2010. The probability of economic emigration in Kosovo. Eastern European Economics 48 (6): 17-35.

Kotorri, M. 2015. An Investigation into Economic Migration. Saarbruecken : Lambert Academic Publishing.

Kotorri, M., Rizvanolli, A., Peci, F., Kotorri, V., Çitaku, F., Zherka, P., and Holzner, M. 2013. Migration and its Impacts from the Perspective of the Economic Development of the Home Country: with Special Reference to Kosovo. a project supported by the University of Fribourg and Swiss Agency for Development and Cooperation (SDC), Fribourg: University of Fribourg, Interfaculty Institute for Central and Eastern Europe.

Little, R. J. A. and Rubin, D. 2002. Statistical Analysis with Missing Data. 2 ed., New Jersey: Wiley-Interscience.

Piracha, M., and Vadean, F. 2010. Return migration and occupational choice: Evidence from Albania. World Development 38 (8): 1141-1155.

Sander, M. 2007. Return Migration and the "Healthy Immigrant Effect". SOEP Paper No. 60.

Waldorf, B. 1995. Determinants of International Return Migration Intentions. The Professional Geographer 47 (2): 125-136. 
Table A1: Variable Lable, Variable Description, and Descriptive Statistics

\begin{tabular}{|c|c|c|c|}
\hline Variables & Description & Mean & $\begin{array}{l}\text { Standard } \\
\text { deviation }\end{array}$ \\
\hline YA & Household income per capita in Kosovo & 1860.30 & 1993.34 \\
\hline YASQ & Household income per capita in Kosovo, squared & & \\
\hline \multicolumn{4}{|c|}{$\begin{array}{l}\text { Household demographic } \\
\text { characteristics }\end{array}$} \\
\hline SWAE & $\begin{array}{c}\begin{array}{c}\text { Share of those of working age who are in } \\
\text { employment }\end{array}\end{array}$ & 83.75 & 32.76 \\
\hline SF & Share of females & 13.25 & 23.47 \\
\hline Edu & $\begin{array}{l}\text { Equals } 1 \text { if the household head has higher edu- } \\
\text { cation, } 0 \text { otherwise }\end{array}$ & 0.15 & 0.35 \\
\hline \multicolumn{4}{|l|}{ Psychic income } \\
\hline Individual & $\begin{array}{l}\text { Equals } 1 \text { if the household consists of only one } \\
\text { member, } 0 \text { otherwise }\end{array}$ & 0.6 & 0.49 \\
\hline Householdsize & $\begin{array}{c}\text { Number of household members within a } \\
\text { household }\end{array}$ & 1.8 & 1.3 \\
\hline Citizenship & $\begin{array}{l}\text { Equals } 1 \text { if the household has the citizenship of } \\
\text { the host country, } 0 \text { otherwise }\end{array}$ & 0.65 & 0.48 \\
\hline Edulnstitution & $\begin{array}{l}\text { Equals } 1 \text { if any of the household members has at- } \\
\text { tained or is attaining education at any institution } \\
\text { abroad, } 0 \text { otherwise }\end{array}$ & 0.21 & 0.41 \\
\hline Houseownership & $\begin{array}{c}\text { Equals } 1 \text { if the household owns a house in the } \\
\text { host country }\end{array}$ & 0.30 & 0.45 \\
\hline Businessownership & $\begin{array}{l}\text { Equals } 1 \text { if the household owns a business in the } \\
\text { host country }\end{array}$ & 0.06 & 0.23 \\
\hline \multicolumn{4}{|l|}{ Political situation } \\
\hline Year1998/99 & $\begin{array}{c}\text { Equals } 1 \text { if household emigrated in } 1998 \text { or } 1999, \\
\text { zero otherwise }\end{array}$ & 0.14 & 0.34 \\
\hline
\end{tabular}


Table A2: The estimated determinants of migration duration, replication of Kotorri (2015)

\begin{tabular}{|c|c|c|c|}
\hline Variable & Hazard Ratio & $P>|t|$ & Expected sign \\
\hline \multicolumn{4}{|l|}{ Household Characteristics } \\
\hline$Y A$ & 0.99 & $0.03^{* *}$ & Greater than 1 \\
\hline YASQ & 1 & 0.95 & Less than 1 \\
\hline SWAE & 0.99 & 0.56 & Less than 1 \\
\hline$S F$ & 0.98 & $0.05^{* *}$ & Greater than 1 \\
\hline Education & 1.12 & 0.78 & Ambiguous \\
\hline \multicolumn{4}{|l|}{ Psychic Income } \\
\hline Individual & 0.73 & 0.51 & Less than 1 \\
\hline Citizenship & 0.32 & $0.01^{* * *}$ & Less than 1 \\
\hline Edulnstitution & 0.47 & 0.12 & Less than 1 \\
\hline \multicolumn{4}{|l|}{ Political situation } \\
\hline Year1998/99 & 3.08 & $0.01^{* * *}$ & Greater than 1 \\
\hline Number of observations & 290 & & \\
\hline Number of failures & 39 & & \\
\hline Time at risk & 4241 & & \\
\hline LR chi2(9) & 62.76 & & \\
\hline Prob>chi2 & 0.001 & & \\
\hline Log likelihood & -150.10 & & \\
\hline $\begin{array}{l}\text { Test of the proportional-hazards based on the } \\
\text { Schoenfeld residuals chi2(12) }\end{array}$ & 16.63 & 0.054 & \\
\hline Harrell's C concordance statistic & 0.84 & & \\
\hline
\end{tabular}

